Revista Brasileira de Agricultura Irrigada v.13, nº.1, p. 3247 - 3261, 2019

ISSN 1982-7679 (On-line)

Fortaleza, CE, INOVAGRI - http://www.inovagri.org.br

DOI: $10.7127 /$ rbai.v13n1001034

Protocolo 1034.19 - 13/11/2018 Aprovado em 28/03/2019

\title{
BALANÇO HÍDRICO E APTIDÃO CLIMÁTICA DE CULTURAS PARA AS MESORREGIÕES DA PARAÍBA
}

\author{
Sandro Roberto Dias Araújo ${ }^{1}$, Patrícia Ferreira da silva ${ }^{2}$, Rigoberto Moreira de Matos ${ }^{3}$, José Dantas \\ Neto $^{4}$, Arsênio Pessoa de Melo Júnior ${ }^{5}$, Luciano Marcelo Fallé Saboya ${ }^{6}$
}

\begin{abstract}
RESUMO
O estudo das condições agroclimáticas permite conhecer o potencial agrícola de uma determinada região, assim, objetivou-se com este estudo avaliar o balanço hídrico climatológico e a aptidão climática de culturas visando disponibilizar informações para a implantação nas mesorregiões da Paraíba. O cálculo do balanço hídrico, elaboração do evapopluviograma e a determinação da aptidão agroclimática das culturas foram realizados a partir de uma série histórica de precipitação e temperatura do ar. O deficit de água no solo é o principal fator determinante das condições para a exploração de uma determinada cultura no estado da Paraíba. As condições agroclimáticas do estado da Paraíba permitiram classificar $80 \%$ das espécies estudadas neste trabalho como aptidão plena, $50 \%$ aptidão moderada e $20 \%$ aptidão restrita. Para garantir a produtividade das culturas, faz-se necessário planejamento agrícola em 100\% das mesorregiões visando à implantação de sistemas de irrigação com uso racional da água em especial nos períodos de estiagem.
\end{abstract}

Palavras-chave: deficit hídrico, condições agroclimáticas, potencial agrícola.

\section{WATER BALANCE AND AGROCLIMATIC FITNESS OF CULTURES FOR THE MESOREGIONS OF PARAÍBA}

\begin{abstract}
\footnotetext{
${ }^{1}$ Mestre em Engenharia Agrícola, UFCG, e-mail: sandrodiasriego@gmail.com

${ }^{2}$ Pós-Doutoranda em Recursos Naturais, UFCG, email: patrycyafs @ yahoo.com.br

${ }^{3}$ Doutorando em Engenharia Agrícola, UFCG, e-mail: rigobertomoreira@gmail.com

${ }^{4}$ Doutor em Agronomia, Prof. Titular da UFCG, e-mail: zedantas1955@ gmail.com

${ }^{5}$ Doutor em Engenharia Agrícola, Prof. do IFPE, e-mail: arseniopessoa@uol.com.br

${ }^{6}$ Doutor em Engenharia Agrícola, Prof. da UFCG, e-mail: 1saboya@ hotmail.com
}

The study of the agroclimatic conditions allows to know the agricultural potential of a certain region, thus, the objective of this study was to evaluate the climatic water balance and the fitness agroclimatic of crops in order to provide information for the implantation in the mesoregions of Paraíba. The calculation of the water balance, elaboration of the evapopluviograma and the determination of the fitness agroclimatic of the cultures were made from a historical series of precipitation and air temperature. The water deficit in the soil is the main factor determinant of the conditions for the exploitation of a certain crop in the state of Paraíba. The agroclimatic conditions of 
the state of Paraíba allowed to classify $80 \%$ of the species studied in this study as full fitness, $50 \%$ moderate fitness and $20 \%$ restricted fitness. To ensure crop productivity, it is necessary to plan $100 \%$ of the mesoregions in agricultural planning, aiming at the implementation of irrigation systems with rational use of water, especially during periods of drought.

Keywords: water deficit, agroclimatic conditions, agricultural potential.

\section{INTRODUÇÃO}

O balanço hídrico climático de uma região é uma variável de relevância, uma vez que o mesmo considera a textura do solo, profundidade efetiva e o movimento de água no solo durante todo o ano (MATOS et al. 2014). A utilização do balanço hídrico de Thornthwaite (1948) e Thornthwaite e Mather (1955), como ferramenta de manejo da irrigação procura nortear ações de planejamento na produção de culturas agrícola para uma dada região, possibilitando maior rentabilidade dos cultivos. Medeiros et al., (2013) relatam que a técnica do balanço hídrico fornece o saldo de água disponível no solo para o vegetal, ou seja, contabiliza a entrada (precipitação e ou irrigação) e a saída (evapotranspiração potencial), considerando determinada capacidade de armazenamento de água pelo solo. O conhecimento do balanço hídrico fornece subsídios para a escolha de culturas adaptadas a uma determinada condição climática predominante.

Nesse contexto, o estudo da aptidão climática de culturas é uma ferramenta que contribui para o desenvolvimento de políticas públicas voltadas para o setor agrícola, assim como, incentiva a implantação de novas áreas de cultivo, abertura de linhas de crédito além de auxiliar na tomada de decisão pelos produtores (SILVA et al., 2013).

Para Matos et al. (2015) com base na aptidão agroclimática de uma região é possível determinar seu potencial agrícola, proporcionando não apenas a escolha das culturas, como também o uso de técnicas de manejo ideal, a exemplo, da necessidade de irrigação durante todo o cultivo, ou parte dele, em períodos secos.
A aptidão climática fornece subsídios para que o agricultor se planeje quanto aos diferentes riscos climáticos, como variações de temperatura, umidade relativa, irregularidades em precipitações, déficit de pressão de vapor, evapotranspiração, insolação e vento considerando-se a região de cultivo (MEDEIROS et al., 2017).

A investigação do clima com base nos índices de aridez (Ia), hídrico (Ih) e de umidade (Iu), propicia o estudo do zoneamento agroclimático determinando assim a aptidão das culturas exploradas, com base no evapopluviograma e no cálculo dos índices de vegetação (Iv), repouso por seca (Irs), repouso por frio (Irf) e hídrico (Ih).

Assim, objetivou-se com este estudo avaliar o balanço hídrico climatológico e a aptidão agroclimática de culturas visando disponibilizar informações para a implantação nas mesorregiões da Paraíba.

\section{MATERIAL E MÉTODOS}

\section{Caracterização da área de estudo}

A área de estudo compreende o estado da Paraíba, localizado na região Nordeste do Brasil, com área de $56.372 \mathrm{~km}^{2}$, correspondendo a $0,66 \%$ do território nacional. Seu posicionamento encontra-se entre os paralelos $6^{\circ} 02^{\prime} 12^{\prime \prime}$ e $8^{\circ} 19^{\prime} 18^{\prime \prime} \mathrm{S}$, e meridianos $34^{\circ} 45^{\prime} 54^{\prime \prime}$ e $38^{\circ} 45^{\prime} 45^{\prime \prime} \mathrm{O}$ (FRANCISCO et al., 2015a). O estado possui seis mesorregiões climáticas: o Alto Sertão (Região 6), Sertão (Região 5), CaririCurimataú (Região 4), Agreste (Região 3), Brejo (Região 2) e Litoral (Região 1) conforme apresentado na Figura 1. 


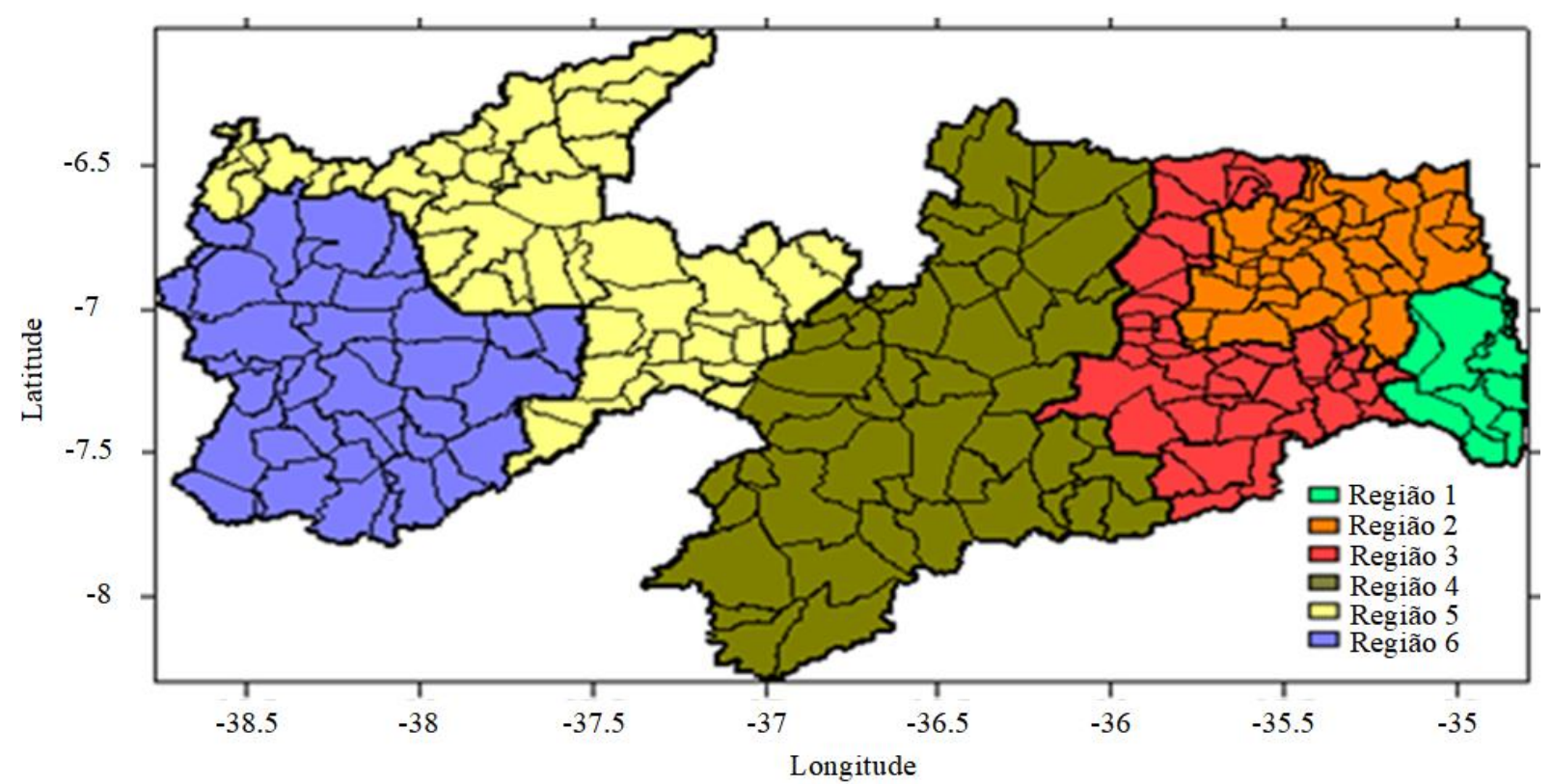

Figura 1. Localização das mesorregiões do estado da Paraíba (BRITO; BRAGA, 2005).

O clima caracteriza-se por temperaturas médias elevadas $\left(22\right.$ a $\left.30^{\circ} \mathrm{C}\right)$ e uma amplitude térmica anual muito pequena, em função da baixa latitude e elevações $(<700 \mathrm{~m})$.

A precipitação varia de 400 a $800 \mathrm{~mm}$ anuais nas regiões semiáridas do interior do estado, e no Litoral, mais úmido, pode ultrapassar $1.600 \mathrm{~mm}$.

No estado da Paraíba os fatores provocadores de chuvas são a Zona de Convergência Intertropical (ZCIT) e os sistemas de Vórtices Ciclônicos de Altos Níveis (VCANs) quando em atividade sobre o Nordeste, além dos efeitos dos ventos alísios em conjunto com os de brisa marítima, auxiliados pelos Vórtices Ciclônicos do Atlântico Sul (VCAS) e das linhas de instabilidade, Padrão do Dipolo no Oceano Atlântico Tropical e as perturbações ondulatórias dos ventos alísios (BECKER et al., 2013).

\section{Determinação do balanço hídrico climatológico}

Para elaboração do balanço hídrico climatológico (BHC), utilizaram-se dados de precipitação fornecidos pela Agência Executiva de Gestão das Águas do Estado da Paraíba (AESA) e pela Superintendência do
Desenvolvimento do Nordeste (SUDENE). Os dados de precipitação referentes ao período histórico de 1971 a 2017 foram obtidos para todos os municípios das mesorregiões do estado da Paraíba. As séries mensais e anuais de precipitação foram selecionadas com base no critério de análise apenas daquelas sem falhas e contínuas, bem como distribuídas homogeneamente na área de estudo. Utilizouse o Estima_T, desenvolvido pelo núcleo de meteorologia da Universidade Federal de Campina Grande, utilizando a técnica da reta de regressão múltipla para estimativa da temperatura do ar (CAVALCANTI et al., 2006).

Para obtenção do balanço hídrico utilizou-se o método de Thornthwaite (1948) e Thornthwaite e Mather (1955), com planilhas eletrônicas que contabilizam a água do solo, em que a precipitação representa ganho $\mathrm{e} a$ evapotranspiração perda de água do solo, podendo-se estimar os valores correspondentes ao excesso hídrico (S) e deficit hídrico (D).

A capacidade de armazenamento de água disponível no solo de $100 \mathrm{~mm}$ e a evapotranspiração potencial foram obtidas conforme equação 1 (THORNTHWAITE, 1948) 


$$
E T p=F C * 16\left(10 \frac{T}{I}\right)^{a}
$$

Em que:

ETp - evapotranspiração potencial, $\mathrm{mm} \mathrm{mês}^{-1}$; $\mathrm{Fc}$ - fator de correção (Tabela 1); $\mathrm{T}$ temperatura média mensal, ${ }^{\circ} \mathrm{C}$; I - índice anual de calor, correspondente a soma dos índices mensais a função cúbica do índice anual de calor (Equação 2).

$$
a=6,75 * 10^{-7} * I^{3}-7,71 * 10^{-5} * I^{2}+0,01791 * I+0,492
$$

Em que:

a - função cúbica do índice anual de calor, $\mathrm{mm} \mathrm{mês}^{-1}$; I - índice

anual de calor, correspondente a soma dos doze índices mensais.

Tabela 1. Fator de correção em função dos meses e da latitude (THORNTHWAITE, 1948).

\begin{tabular}{ccccccccccccc}
\hline Latitude & Jan & Fev & Mar & Abr & Mai & Jun & Jul & Ago & Set & Out & Nov & Dez \\
\hline $0^{\circ}$ & 1,03 & 0,93 & 1,03 & 1,00 & 1,03 & 1,00 & 1,03 & 1,03 & 1,00 & 1,03 & 1,00 & 1,03 \\
$2^{\circ} \mathrm{S}$ & 1,04 & 0,94 & 1,04 & 1,00 & 1,03 & 0,99 & 1,02 & 1,02 & 0,99 & 1,03 & 1,00 & 1,04 \\
$4^{\circ} \mathrm{S}$ & 1,05 & 0,95 & 1,04 & 1,00 & 1,03 & 0,98 & 1,01 & 1,02 & 0,99 & 1,03 & 1,01 & 1,05 \\
$6^{\circ} \mathrm{S}$ & 1,06 & 0,96 & 1,05 & 1,00 & 1,02 & 0,98 & 1,00 & 1,01 & 0,98 & 1,03 & 1,01 & 1,06 \\
$8^{\circ} \mathrm{S}$ & 10,7 & 0,97 & 1,06 & 1,00 & 1,02 & 0,97 & 0,99 & 1,00 & 0,98 & 1,03 & 1,01 & 1,06 \\
$10^{\circ} \mathrm{S}$ & 1,08 & 0,97 & 1,06 & 1,00 & 1,01 & 0,96 & 0,98 & 0,99 & 0,97 & 1,03 & 1,02 & 1,07 \\
\hline
\end{tabular}

Fonte: Unesco (1982).

\section{Elaboração do evapopluviograma}

Elaborou-se o evapopluviograma de cada mesorregião, o qual se refere a um climograma adaptado ao BHC, para fins de estudo das condições climáticas mais adequadas às culturas, pelo sistema de coordenadas ortogonais, onde a evapotranspiração potencial é plotada em função da precipitação, assim obtendo-se o evapopluviograma

(THORNTHWAITE, 1948). O diagrama apresenta-se dividido em seis setores hídricos, nos quais os valores da precipitação correspondem a diferentes

$$
\begin{aligned}
& I h=N^{\circ} P * V \\
& I v=N^{\circ} P * V \\
& I r s=N^{\circ} P * V \\
& I r f=N^{\circ} P * V
\end{aligned}
$$


Em que:

$\mathrm{N}^{\mathrm{o}} \mathrm{P}$ - número de pontos do evapopluviograma dentro de cada setor hídrico e faixa térmica; V - valor dos Ih, Iv, Irs e Irf dentro de cada setor hídrico e faixa térmica.

\section{Determinação da aptidão climática}

Os valores dos índices foram aplicados na Tabela 2 para determinação da aptidão climática das culturas, classificando-as em aptidão plena, moderada, restrita e inaptidão.

Tabela 2. Resumo da aptidão climática para as culturas do abacaxi, algodão herbáceo, banana, caju, cana-de-açúcar, feijão, milho, mamona, sisal e sorgo.

\begin{tabular}{|c|c|c|c|}
\hline$\frac{\widetilde{a}}{\stackrel{\Xi}{\Xi}}$ & 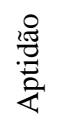 & $\begin{array}{l}\text { Índice } \\
\text { Climático }\end{array}$ & Deficiência/excesso \\
\hline 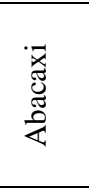 & $\begin{array}{l}\mathrm{P} \\
\mathrm{M} \\
\mathrm{R}\end{array}$ & $\begin{aligned} &-20 \leq \mathrm{I}_{\mathrm{h}}<20 \\
& \mathrm{I}_{\mathrm{h}}>20 \\
&-20 \leq \mathrm{I}_{\mathrm{h}}<-20 \\
&-40 \leq \mathrm{I}_{\mathrm{h}}<-30 \\
& \mathrm{I}_{\mathrm{h}}<-40\end{aligned}$ & $\begin{array}{l}\Rightarrow \text { Boas condições hídricas e térmicas ao desenvolvimento da cultura } \\
\Rightarrow \text { Umidade excessiva prejudicandoo desenvolvimento da cultura } \\
\Rightarrow \text { Restrições hídricas para o desenvolvimento da cultura } \\
\Rightarrow \text { Limitações ao cultivo por deficiência hídrica acentuada } \\
\Rightarrow \text { Déficit hídrico severo, cultivo somente com irrigação }\end{array}$ \\
\hline 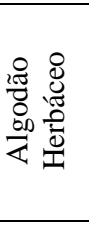 & $\begin{array}{l}\mathrm{P} \\
\mathrm{M}\end{array}$ & $\begin{array}{c}30 \leq \mathrm{I}_{\mathrm{v}}<50, \mathrm{I}_{\mathrm{rss}} \geq 4 \\
30<\mathrm{I}_{\mathrm{v}}<50, \mathrm{I}_{\mathrm{rs}} \geq 4 \\
30<\mathrm{I}_{\mathrm{v}}<50 \\
\mathrm{I}_{\mathrm{Sv}} \leq 1, \mathrm{I}_{\mathrm{rs}}<4 \\
20<\mathrm{I}_{\mathrm{v}}<30, \mathrm{I}_{\mathrm{sv}}>1 \\
\mathrm{I}_{\mathrm{v}}>50, \mathrm{I}_{\mathrm{v}}<20\end{array}$ & $\begin{array}{l}\Rightarrow \text { Boas condições hídricas e térmicas ao desenvolvimento da cultura } \\
\Rightarrow \text { Período vegetativonormal, mas comocorrência de seca } \\
\Rightarrow \text { Repousoporsecainsuficiente para maturação dafibra } \\
\Rightarrow \text { Período vegetativo curto com ocorrência de seca } \\
\Rightarrow \text { Umidade excessiva para o desenvolvimento da cultura } \\
\Rightarrow \text { Ocorrência de seca durante todo o ciclo da cultura }\end{array}$ \\
\hline 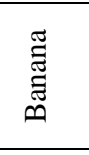 & $\begin{array}{l}\mathrm{P} \\
\mathrm{M} \\
\mathrm{R} \\
\mathrm{I}\end{array}$ & $\begin{array}{c}\mathrm{D}<200 \mathrm{~mm} \\
200<\mathrm{D}<350 \mathrm{~mm} \\
350<\mathrm{D}<700 \mathrm{~mm} \\
\mathrm{D}>700 \mathrm{~mm} \\
\end{array}$ & $\begin{array}{l}\Rightarrow \text { Boas condições hídricas aodesenvolvimento da cultura } \\
\Rightarrow \text { Insuficiência hídrica estacional, prolongando o ciclo da cultura } \\
\Rightarrow \text { Deficiência hídrica acentuada, cultivo em locais mais úmidos } \\
\Rightarrow \text { Déficit hídrico muito severo, cultivo somente com irrigação }\end{array}$ \\
\hline 写 & $\begin{array}{l}\mathrm{P} \\
\mathrm{M} \\
\mathrm{R}\end{array}$ & $\begin{array}{c}\mathrm{I}_{\mathrm{h}}>-10, \mathrm{D}<100 \mathrm{~mm} \\
\mathrm{I}_{\mathrm{h}}<-10,100<\mathrm{D}<200 \\
200<\mathrm{D}<700 \mathrm{~mm} \\
700<\mathrm{D}<900 \mathrm{~mm} \\
\mathrm{D}>700 \mathrm{~mm} \\
\end{array}$ & $\begin{array}{l}\Rightarrow \text { Sem limitações climáticas, principalmente em climasquentes } \\
\Rightarrow \text { Ocorrência normal de pequena deficiência hídrica } \\
\Rightarrow \text { Cultivo parcialmente prejudicado pela deficiência hídrica } \\
\Rightarrow \text { Déficit hídrico severo na maioria dos solos, cultivo irrigado } \\
\Rightarrow \text { Suprimento hídrico insuficiente para a cultura }\end{array}$ \\
\hline 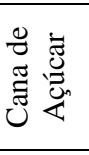 & $\begin{array}{l}\mathrm{P} \\
\mathrm{M} \\
\mathrm{R} \\
\mathrm{I}\end{array}$ & $\begin{array}{c}\mathrm{I}_{\mathrm{h}}>0, \mathrm{D}<200 \mathrm{~mm} \\
\mathrm{I}_{\mathrm{h}}>0, \mathrm{D}>200 \mathrm{~mm} \\
0>\mathrm{I}_{\mathrm{h}}>-10 \\
\mathrm{I}_{\mathrm{h}}<-10\end{array}$ & $\begin{array}{l}\Rightarrow \text { Boas condições hídricas aodesenvolvimento da cultura } \\
\Rightarrow \text { Seca estacional. Cultivo recomendado em várzeas úmidas } \\
\Rightarrow \text { Seca estacional intensa. Cultivo com irrigação suplementar } \\
\Rightarrow \text { Carênciahídrica muito severa para acultura }\end{array}$ \\
\hline 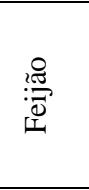 & $\begin{array}{l}\mathrm{P} \\
\mathrm{M} \\
\mathrm{R}\end{array}$ & $\begin{aligned} \mathrm{I}_{\mathrm{v}}>30,1<\mathrm{I}_{\mathrm{rs}}<5 \\
\mathrm{D}<20 \mathrm{~mm}, \mathrm{~T}_{\mathrm{a}}>22^{\circ} \mathrm{C} \\
25<\mathrm{I}_{\mathrm{v}}<30 \\
\mathrm{D}>20 \mathrm{~mm}, \mathrm{~T}_{\mathrm{a}}>22^{\circ} \mathrm{C} \\
2<\mathrm{I}_{\mathrm{v}}<25, \mathrm{D}>20 \mathrm{~mm} \\
\end{aligned}$ & $\begin{array}{l}\Rightarrow \text { Melhores condições climáticas ao desenvolvimento da cultura } \\
\Rightarrow \text { Período vegetativo curto } \\
\Rightarrow \text { Aptidão plena para variedades precoces } \\
\Rightarrow \text { Déficit hídrico acentuado, necessitando de água por irrigação } \\
\Rightarrow \text { Insuficiência hídrica acentuada. Cultivo possível com irrigação }\end{array}$ \\
\hline$\stackrel{8}{\stackrel{\Xi}{\Sigma}}$ & $\begin{array}{l}\mathrm{P} \\
\mathrm{M}\end{array}$ & $\begin{array}{c}40<\mathrm{I}_{\mathrm{V}}<60, \mathrm{D}>0 \\
\mathrm{~T}>19^{\circ} \mathrm{C} \\
30<\mathrm{I}_{\mathrm{v}}<40, \mathrm{D}<0 \\
\mathrm{~S}<500 \mathrm{~mm}, \mathrm{I}_{\mathrm{V}}<20 \\
\mathrm{I}_{\mathrm{h}}>-10, \mathrm{D}>100 \mathrm{~mm}\end{array}$ & $\begin{array}{l}\Rightarrow \text { Condições hídricas e térmicas satisfatórias para acultura } \\
\Rightarrow \text { Pequena insuficiência hídrica no período vegetativo, umidade excessiva na } \\
\text { maturação. Aptidão plena para variedades precoces } \\
\Rightarrow \text { Déficit hídrico severo ou insuficiência térmica para a cultura } \\
\Rightarrow \text { Deficiênciahídricamuitosevera, tornandoinviávelocultivo }\end{array}$ \\
\hline 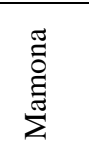 & $\begin{array}{l}\mathrm{P} \\
\mathrm{M} \\
\mathrm{R} \\
\mathrm{I}\end{array}$ & $\begin{array}{c}\mathrm{D}>60 \mathrm{~mm}, \mathrm{~T}>20^{\circ} \mathrm{C} \\
0<\mathrm{D}<60, \mathrm{~T}>20^{\circ} \mathrm{C} \\
\mathrm{D}>100 \mathrm{~mm}, \mathrm{~T}<19^{\circ} \mathrm{C} \\
\mathrm{I}_{\mathrm{h}}<-40\end{array}$ & $\begin{array}{l}\Rightarrow \text { Condições hídricas e térmicas para quaisquer variedades } \\
\Rightarrow \text { Pequeno déficit hídrico, exceto variedades resistentes à secas } \\
\Rightarrow \text { Áreas muito úmidas ou secas. Insuficiência térmica } \\
\Rightarrow \text { Déficit hídrico elevado prejudicando desenvolvimento cultura }\end{array}$ \\
\hline 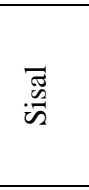 & $\begin{array}{l}\mathrm{P} \\
\mathrm{M} \\
\mathrm{R} \\
\mathrm{I}\end{array}$ & $\begin{array}{c}\mathrm{I}_{\mathrm{h}}>-10, \mathrm{D}>100 \\
-30<\mathrm{I}_{\mathrm{V}}<-10 \\
-40<\mathrm{D}<-30 \mathrm{~mm} \\
\mathrm{I}_{\mathrm{h}}<-40 \mathrm{~mm}\end{array}$ & $\begin{array}{l}\Rightarrow \text { Boas condições hídricas aodesenvolvimentoda cultura } \\
\Rightarrow \text { Déficit hídrico prejudicando o desenvolvimento da cultura } \\
\Rightarrow \text { Umidade excessiva no período vegetativo } \\
\Rightarrow \text { Déficit hídrico acentuado, prejudicando a cultura } \\
\Rightarrow \text { Déficit hídrico muito severo tornando inviável o cultivo }\end{array}$ \\
\hline $\begin{array}{l}\text { o } \\
\dot{0} \\
\stackrel{0}{ }\end{array}$ & $\begin{array}{l}\mathrm{P} \\
\mathrm{M} \\
\mathrm{R} \\
\mathrm{I}\end{array}$ & $\begin{array}{c}20<\mathrm{I}_{\mathrm{v}}<30, \\
\mathrm{D}>200 \mathrm{~mm}, \mathrm{~T}_{\mathrm{a}}>18^{\circ} \mathrm{C} \\
30<\mathrm{I}_{\mathrm{V}}<40, \mathrm{~s}<500 \\
40<\mathrm{I}_{\mathrm{v}}<60, \mathrm{I}_{\mathrm{v}}>60\end{array}$ & $\begin{array}{l}\Rightarrow \text { Condições hídricas e térmicas satisfatórias para a cultura } \\
\Rightarrow \text { Excesso hídrico afetando a produção da cultura } \\
\Rightarrow \text { Restrições por excesso hídrico acentuado } \\
\Rightarrow \text { Não recomendado para o cultivo do sorgo }\end{array}$ \\
\hline
\end{tabular}

Legenda: P - plena, M - moderada, R - restrita, I - inaptidão, Ih - índice hídrico, Iv - índice vegetativo, Irs - índice de repouso por seca, Isv - índice de seca na vegetação, T - temperatura média, D - Deficiência hídrica e S - excesso hídrico. Fonte: Ometto (1981). 
RESULTADOS E DISCUSSÃO

\section{Balanço hídrico climatológico}

O balanço hídrico da série histórica de
$1971 \quad$ a -2017

climáticos para do Sertão e Sertão da Paraíba encontram-se na Tabela 3.

Tabela 3. Balanço hídrico climatológico médio anual para as mesorregiões do Alto Sertão e Sertão do estado da Paraíba.

\begin{tabular}{|c|c|c|c|c|c|c|c|c|c|c|}
\hline & \multicolumn{5}{|c|}{ Alto Sertão } & \multicolumn{5}{|c|}{ Sertão } \\
\hline \multirow{2}{*}{ Meses } & $\mathrm{T}$ & $\mathrm{P}$ & ETp & $\mathrm{D}$ & $S$ & $\mathrm{~T}$ & $\mathrm{P}$ & ETp & $\mathrm{D}$ & $S$ \\
\hline & $\left({ }^{\circ} \mathrm{C}\right)$ & \multicolumn{4}{|c|}{--------------- $(\mathrm{mm})$-------------- } & $\left({ }^{\circ} \mathrm{C}\right)$ & \multicolumn{4}{|c|}{------------- (mm) ----------- } \\
\hline Jan & 25,4 & 110,5 & 124,2 & 13,7 & 0,0 & 25,7 & 82,8 & 128,9 & 46,0 & 0,0 \\
\hline Fev & 25,1 & 155,7 & 111,4 & 0,0 & 0,0 & 25,5 & 125,4 & 115,6 & 0,0 & 0,0 \\
\hline Mar & 24,9 & 221,3 & 117,6 & 0,0 & 48,2 & 25,2 & 190,3 & 121,3 & 0,0 & 0,0 \\
\hline Abr & 24,4 & 176,7 & 105,1 & 0,0 & 71,6 & 24,6 & 171,3 & 108,2 & 0,0 & 41,9 \\
\hline Mai & 23,6 & 78,6 & 97,1 & 1,6 & 0,0 & 23,9 & 84,3 & 100,3 & 1,2 & 0,0 \\
\hline Jun & 22,7 & 33,2 & 82,8 & 17,1 & 0,0 & 23,1 & 35,2 & 85,7 & 16,7 & 0,0 \\
\hline Jul & 22,4 & 17,2 & 81,2 & 40,1 & 0,0 & 22,7 & 18,6 & 84,0 & 40,7 & 0,0 \\
\hline Ago & 22,8 & 5,9 & 86,8 & 66,2 & 0,0 & 23,0 & 6,2 & 88,5 & 67,3 & 0,0 \\
\hline Set & 24,0 & 5,3 & 99,8 & 87,2 & 0,0 & 24,1 & 2,6 & 100,9 & 90,9 & 0,0 \\
\hline Out & 24,9 & 12,0 & 117,4 & 102,5 & 0,0 & 25,1 & 6,5 & 119,1 & 109,7 & 0,0 \\
\hline Nov & 25,3 & 19,1 & 121,5 & 101,4 & 0,0 & 25,6 & 9,5 & 124,8 & 114,4 & 0,0 \\
\hline Dez & 25,4 & 46,0 & 128,9 & 82,6 & 0,0 & 25,8 & 29,0 & 133,6 & 104,3 & 0,0 \\
\hline
\end{tabular}

Legenda: Temperatura média do ar (T), Precipitação pluvial (P), Evapotranspiração potencial (ETp), Deficiência hídrica (D) e Excesso hídrico (S).

A mesorregião do Alto Sertão possui temperatura média do ar anual de $24,2{ }^{\circ} \mathrm{C}$, com mínima de $22,4{ }^{\circ} \mathrm{C}$ ocorrida no mês de julho e máxima de $25,4{ }^{\circ} \mathrm{C}$ incidida em dezembro e janeiro. No Sertão a temperatura média anual é de $24,5^{\circ} \mathrm{C}$, com mínima de 22,7 ${ }^{\circ} \mathrm{C}$ incidida no mês de julho e máxima de 25,8 ${ }^{\circ} \mathrm{C}$ ocorrida em dezembro.

De acordo com Francisco et al. (2015b), a região do Alto Sertão possui temperatura média de $24,2{ }^{\circ} \mathrm{C}$, mínima de $22,4{ }^{\circ} \mathrm{C}$ no mês de julho e máxima de $25,4{ }^{\circ} \mathrm{C}$ nos meses de dezembro e janeiro, enquanto que no Sertão Paraibano a média é de $25,7{ }^{\circ} \mathrm{C}$, oscilando de $22,7{ }^{\circ} \mathrm{C}$ no mês de julho a $25,7{ }^{\circ} \mathrm{C}$ nos meses de dezembro e janeiro. Estes resultados corroboram com os obtidos no presente estudo.

A precipitação anual é de $881,5 \mathrm{~mm}$ no Alto Sertão, sendo o período mais chuvoso de janeiro a abril (oscilando de 110,5 a 221,3 mm mês ${ }^{-1}$ ) e os meses de maior escassez de chuvas de julho a novembro (variando de 5,3 a 19,1 $\mathrm{mm}$ mês $^{-1}$ ). No Sertão a temporada chuvosa ocorre de janeiro a maio (com valores de 82,8 a 190,3 mm mês ${ }^{-1}$ ) e de julho a novembro apresentam os menores valores de precipitação (variando de 2,6 a 18,6 mm mês ${ }^{-1}$ ), e média anual de 761,6 mm. Observa-se que o Sertão possui uma menor média anual de precipitação em relação à registrada no Alto Sertão.

Silva e Lucena (2015) relataram que o Alto Sertão apresenta alta variabilidade da precipitação pluviométrica, com média anual de $857,0 \mathrm{~mm}$. Francisco et al. (2015b) observaram precipitação média anual de 757,2 $\mathrm{mm}$ para o Sertão, sendo que de janeiro a maio ocorreram $86 \%$ dos índices pluviométricos registrados. Os resultados obtidos nas pesquisas destes autores são semelhantes aos observados no presente estudo.

Verificou-se na mesorregião do Alto Sertão uma evapotranspiração potencial anual de $1.273,9 \mathrm{~mm}$, oscilando de 81,2 a $128,9 \mathrm{~mm}$ mês $^{-1}$, sendo as maiores taxas evapotranspiradas nos meses de outubro a março.

Já no Sertão Paraibano a média anual da evapotranspiração potencial é de $1.311,0 \mathrm{~mm}$, com variações de 84,0 a 133,6 mm mês ${ }^{-1}$, onde 
de outubro a março ocorre as maiores taxas de água evapotranspirada.

Medeiros et al. (2015a) afirmam que a evapotranspiração anual destas regiões é de $1.230,2 \mathrm{~mm}$, variando de 102,8 a $125,6 \mathrm{~mm}$ mês ${ }^{-1}$, onde as maiores evapotranspirações ocorrem de outubro a abril, reafirmando os dados obtidos no presente estudo.

No Alto Sertão a deficiência hídrica anual é de $512,3 \mathrm{~mm}$, onde os meses de janeiro a junho apresentam os menores déficits hídricos e as maiores deficiências de água no solo ocorrem de julho a dezembro. No Sertão a deficiência hídrica anual é de 591,2 mm, com os menores déficits de água no solo nos meses de fevereiro a junho e os maiores de julho a janeiro. O excesso hídrico anual é de $119,9 \mathrm{~mm}$ no Alto Sertão, sendo verificado excedente hídrico somente de março a abril, já no Sertão o excesso de água no solo anual é de 41,9 mm, constatado apenas no mês de abril.

Devido às regiões do Alto Sertão e Sertão apresentarem baixo excesso de água e alta deficiência hídrica, o monitoramento da umidade do solo deve ser cuidadosamente analisado, pois segundo Santos et al., (2010) a deficiência hídrica é causada principalmente pela irregularidade da precipitação e sua má distribuição anual. Passos et al., (2017) relatam que nessas regiões a necessidade do uso de irrigação suplementar nas áreas irrigadas é evidente, pois essas regiões passam por oito a nove meses com deficiência de água no solo.

O balanço hídrico da série histórica de 1971 a 2017 de dados climáticos para as mesorregiões do Cariri-Curimataú e Agreste da Paraíba encontram-se na Tabela 4.

Tabela 4. Balanço hídrico climatológico médio anual para as mesorregiões do Cariri-Curimataú e Agreste do estado da Paraíba.

\begin{tabular}{|c|c|c|c|c|c|c|c|c|c|c|}
\hline & \multicolumn{5}{|c|}{ Cariri-Curimataú } & \multicolumn{5}{|c|}{ Agreste } \\
\hline \multirow{2}{*}{ Meses } & $\mathrm{T}$ & $\mathrm{P}$ & ETp & $\mathrm{D}$ & $\mathrm{S}$ & $\mathrm{T}$ & $\mathrm{P}$ & ETp & $\mathrm{D}$ & $S$ \\
\hline & $\left({ }^{\circ} \mathrm{C}\right)$ & - n & ------ ( & m) ----- & ---- & $\left({ }^{\circ} \mathrm{C}\right)$ & --- & ------ ( & ) --- & \\
\hline Jan & 24,6 & 43,6 & 115,3 & 71,7 & 0,0 & 25,8 & 49,0 & 129,8 & 79,7 & 0,0 \\
\hline Fev & 24,3 & 68,0 & 103,7 & 35,7 & 0,0 & 25,6 & 64,0 & 118,3 & 53,8 & 0,0 \\
\hline Mar & 24,1 & 112,6 & 110,2 & 0,0 & 0,0 & 25,3 & 104,5 & 124,6 & 20,0 & 0,0 \\
\hline Abr & 23,4 & 106,2 & 96,2 & 0,0 & 0,0 & 24,6 & 122,9 & 108,9 & 0,0 & 0,0 \\
\hline Mai & 22,5 & 61,0 & 87,9 & 24,0 & 0,0 & 23,8 & 112,1 & 99,3 & 0,0 & 0,0 \\
\hline Jun & 21,4 & 47,3 & 73,1 & 23,6 & 0,0 & 22,7 & 125,7 & 82,7 & 0,0 & 0,0 \\
\hline Jul & 20,9 & 37,7 & 70,6 & 30,9 & 0,0 & 22,2 & 117,6 & 79,4 & 0,0 & 8,5 \\
\hline Ago & 21,0 & 16,4 & 72,9 & 54,2 & 0,0 & 22,2 & 63,5 & 80,2 & 1,3 & 0,0 \\
\hline Set & 22,3 & 7,5 & 84,5 & 75,4 & 0,0 & 23,3 & 33,9 & 91,0 & 20,3 & 0,0 \\
\hline Out & 23,4 & 6,4 & 101,5 & 94,2 & 0,0 & 24,4 & 13,2 & 110,7 & 67,7 & 0,0 \\
\hline Nov & 24,1 & 6,9 & 108,1 & 100,9 & 0,0 & 25,2 & 14,4 & 119,7 & 93,6 & 0,0 \\
\hline Dez & 24,4 & 17,8 & 117,0 & 99,1 & 0,0 & 25,7 & 22,8 & 132,3 & 105,3 & 0,0 \\
\hline
\end{tabular}

Legenda: Temperatura média do ar (T), Precipitação pluvial (P), Evapotranspiração potencial (ETp), Deficiência hídrica (D) e Excesso hídrico (S).

$\mathrm{Na}$ mesorregião do Cariri-Curimataú a temperatura média anual é de $23,0{ }^{\circ} \mathrm{C}$, sendo julho o mês mais frio $\left(20,9^{\circ} \mathrm{C}\right)$ e janeiro o mais quente do ano $\left(24,6{ }^{\circ} \mathrm{C}\right)$. O Agreste Paraibano possui uma temperatura média anual de $24,2{ }^{\circ} \mathrm{C}$, onde a mínima é de $22,2{ }^{\circ} \mathrm{C}$ ocorrida de julho a agosto e máxima de 25,8 ${ }^{\circ} \mathrm{C}$ advinda no mês de janeiro.

Nas mesorregiões do Cariri-Curimataú e Agreste Paraibano a temperatura do ar oscila entre $21,4{ }^{\circ} \mathrm{C}$ a $24,4{ }^{\circ} \mathrm{C}$, onde estas flutuações são decorrentes da orografia e das condições locais de cada região (MEDEIROS et al., 2017).

A precipitação destas mesorregiões é distribuída de forma irregular, onde no CaririCurimataú a média anual é de 531,5 mm, com as maiores chuvas ocorridas de fevereiro a maio, oscilando de 61,0 a $112,6 \mathrm{~mm} \mathrm{mês}^{-1}$. No Agreste a média anual é de 843,6 mm, sendo 
os maiores valores observados de março a julho, flutuando de 104,5 a $125,7 \mathrm{~mm}$ e total de 582,8 mm durante o período mais chuvoso.

Segundo Morais Neto et al. (2007) a região paraibana é caracterizada por possuir baixas médias pluviométricas e altos índices de evapotranspiração, em função da distribuição pluviométrica se dá em um período muito curto do ano, com uma distribuição temporal e espacial bastante irregular.

A evapotranspiração potencial anual do Cariri-Curimataú é de 1.141,1 mm, com oscilações de 70,6 a 117,0 mm mês ${ }^{-1}$, sendo as maiores taxas evapotranspiradas observadas em dezembro e janeiro. No Agreste Paraibano a média anual da evapotranspiração é de $1.276,8 \mathrm{~mm}$, com flutuações de 79,4 a 132,3 mm mês ${ }^{-1}$, onde nos meses de dezembro e janeiro ocorrem as maiores taxas de água evapotranspirada.

Francisco et al. (2017) relataram que esses valores de evapotranspiração estão intimamente relacionados com a disponibilidade hídrica da região. Matos et al. (2014) ao estudar a aptidão climática por meio do balanço hídrico, verificaram que quando houve um maior índice de precipitação, ocorreu um aumento na evapotranspiração.
Constatou-se que não houve excesso hídrico na mesorregião do Cariri-Curimataú, podendo ser justificado pelo fato da precipitação ser menor que a evapotranspiração. Já no Agreste o excesso hídrico anual é de apenas $8,5 \mathrm{~mm}$, ocorrido no mês de julho.

A deficiência hídrica anual no CaririCurimataú é de 609,6 mm, onde de setembro a janeiro ocorrem os maiores déficits de água no solo, variando de 71,7 a 100,9 mm mês ${ }^{-1}$. No Agreste a deficiência hídrica anual é de 441,7 $\mathrm{mm}$, sendo os maiores déficits hídricos constatados de novembro a janeiro, oscilando de 79,7 a 105,3 $\mathrm{mm} \mathrm{mês}^{-1}$.

No período que ocorre maior perda de água do solo, com valores elevados de déficit hídrico, é recomendável complementar a lâmina de água no solo através da irrigação (NEVES et al., 2011). Ressalta-se que as condições hídricas e climáticas da região devem ser consideradas no zoneamento agroclimático, visando à produção de culturas economicamente rentáveis (WOLLMANN; GALVANI, 2013).

O balanço hídrico da série histórica de 1971 a 2017 de dados climáticos para as mesorregiões do Brejo e Litoral do estado da Paraíba encontram-se na Tabela 5.

Tabela 5. Balanço hídrico climatológico médio anual para as mesorregiões do Brejo e Litoral do estado da Paraíba.

\begin{tabular}{ccccccccccc}
\hline & \multicolumn{9}{c}{ Brejo } & \multicolumn{7}{c}{ Litoral } \\
\hline \multirow{2}{*}{ Meses } & T & P & ETp & D & S & T & P & ETp & D & S \\
\cline { 2 - 10 } & $\left({ }^{\circ} \mathrm{C}\right)$ & ------------- & $(\mathrm{mm})-----------$ & $\left({ }^{\circ} \mathrm{C}\right)$ & $-----------(\mathrm{mm})$ & ----------- \\
\hline Jan & 26,3 & 71,4 & 138,4 & 65,9 & 0,0 & 27,2 & 83,4 & 152,8 & 67,4 & 0,0 \\
Fev & 26,2 & 85,6 & 126,4 & 40,3 & 0,0 & 27,2 & 105,7 & 141,7 & 35,4 & 0,0 \\
Mar & 25,9 & 129,9 & 132,1 & 2,2 & 0,0 & 26,8 & 160,7 & 147,4 & 0,0 & 0,0 \\
Abr & 25,3 & 150,8 & 116,1 & 0,0 & 0,0 & 26,2 & 212,7 & 130,3 & 0,0 & 0,0 \\
Mai & 24,5 & 143,1 & 106,4 & 0,0 & 0,0 & 25,4 & 238,8 & 119,4 & 0,0 & 116,5 \\
Jun & 23,5 & 160,5 & 89,3 & 0,0 & 43,2 & 24,5 & 295,3 & 100,4 & 0,0 & 194,9 \\
Jul & 23,0 & 141,3 & 85,8 & 0,0 & 55,4 & 23,9 & 223,0 & 95,8 & 0,0 & 127,2 \\
Ago & 23,0 & 86,3 & 86,3 & 0,0 & 0,0 & 23,8 & 133,7 & 95,0 & 0,0 & 38,7 \\
Set & 23,9 & 42,2 & 96,9 & 12,6 & 0,0 & 24,6 & 67,7 & 104,3 & 6,0 & 0,0 \\
Out & 25,0 & 16,0 & 117,8 & 64,9 & 0,0 & 25,7 & 26,5 & 127,9 & 57,2 & 0,0 \\
Nov & 25,8 & 18,8 & 127,8 & 95,1 & 0,0 & 26,5 & 27,2 & 139,5 & 95,4 & 0,0 \\
Dez & 26,3 & 29,9 & 142,0 & 107,4 & 0,0 & 23,6 & 25,2 & 97,7 & 68,2 & 0,0 \\
\hline
\end{tabular}

Legenda: Temperatura média do ar (T), Precipitação pluvial (P), Evapotranspiração potencial (ETp), Deficiência hídrica (D) e Excesso hídrico (S). 
A temperatura média do ar no Brejo Paraibano é de $24,9{ }^{\circ} \mathrm{C}$, mínima de $23,0{ }^{\circ} \mathrm{C}$ nos meses de julho a agosto e máxima de 26,3 ${ }^{\circ} \mathrm{C}$ de dezembro a janeiro. No Litoral Paraibano a temperatura média é de $25,5{ }^{\circ} \mathrm{C}$, mínima de $23,8^{\circ} \mathrm{C}$ incidida em dezembro e máxima de $27,2{ }^{\circ} \mathrm{C}$ ocorrida nos meses de janeiro e fevereiro.

De acordo com Cavalcanti et al., (2011) o conhecimento da temperatura do ar de uma dada região a ser implantada o cultivo de uma determinada cultura deve ser considerada, pois cada região possui uma faixa de temperatura adequada para o desenvolvimento fisiológico das plantas, e quando os intervalos se encontram fora dessa faixa a planta não se desenvolve satisfatoriamente.

A precipitação pluviométrica do Brejo é distribuída de forma irregular com média anual de 1.075,7 mm, onde as maiores chuvas ocorrem de março a julho, oscilando de 129,9 a $160,5 \mathrm{~mm}$. No Litoral a distribuição da precipitação também é irregular, com média anual de 1.599,9 $\mathrm{mm}$, sendo que as maiores chuvas ocorrem de fevereiro a agosto, variando de 105,7 a $295,3 \mathrm{~mm}$ no período chuvoso.

Medeiros et al. (2015a) relatam que nestas regiões não apresentam tendência de crescimento dos índices pluviométricos, podendo estes valores serem alterados devido à grande variabilidade espacial e temporal da precipitação, e desta forma, terem um comportamento diferente do previsto, com aumento, diminuição ou ficarem dentro do intervalo esperado. Esse fato reafirma os dados obtidos neste estudo, visto que ocorrem oscilações pluviométricas na maior parte do ano.

No Brejo Paraibano a evapotranspiração potencial anual é de $1.365,4 \mathrm{~mm}$, com oscilações de 85,8 a 142,0 mm mês ${ }^{-1}$, onde as maiores taxas evapotranspirada ocorrem de outubro a maio. A mesorregião do Litoral Paraibano possui uma evapotranspiração anual de $1.452,2 \mathrm{~mm}$, com variações de 95,0 a 152,8 $\mathrm{mm}$ mês $^{-1}$, sendo que de outubro a maio ocorrem as maiores perdas de água através da evapotranspiração. Francisco et al. (2017) relatam que no Brejo a evapotranspiração potencial é de $1.450,0 \mathrm{~mm}^{2} \mathrm{ano}^{-1}$, já no Litoral a evapotranspiração média e de $1.500,0 \mathrm{~mm}$ ano $^{-1}$, e que estas taxas evapotranspirada podem estar atribuídas à disponibilidade hídrica de cada mesorregião, além das condições de solo e vegetação locais.A deficiência hídrica anual no Brejo é de 388,4 $\mathrm{mm}$, onde os maiores déficits de água no solo ocorrem de outubro a janeiro, variando de 64,5 a $107,4 \mathrm{~mm}$ mês $^{-1}$. No Litoral a média anual do déficit hídrico é de $329,6 \mathrm{~mm}$, sendo observados os maiores déficits de água de outubro a janeiro, oscilando de 57,2 a 95,4 mm mês ${ }^{-1}$.

No Brejo ocorre excesso de água no solo apenas em junho e julho, com média anual de 98,7 $\mathrm{mm}$, e no Litoral acontece excesso de água de maio a agosto e total anual de 477,3 $\mathrm{mm}$. Matos et al. (2015) verificaram que de novembro a janeiro ocorrem os maiores déficits de água no Litoral, oscilando de 72,7 a $97,6 \mathrm{~mm} \mathrm{mês}^{-1}$ e total anual de $322,1 \mathrm{~mm}$. Os excedentes hídricos incidem de abril a agosto, oscilando de 45,2 a $221,5 \mathrm{~mm} \mathrm{mês}^{-1}$ e valor anual de 673,8 mm. Resultados estes diferentes dos observados no presente estudo.

\section{Evapopluviogramas}

Os evapopluviogramas foram confeccionados a partir do balanço hídrico e da relação entre evapotranspiração e precipitação de cada mesorregião - Paraíba (Figura 2). 
Araújo et al.

(A)

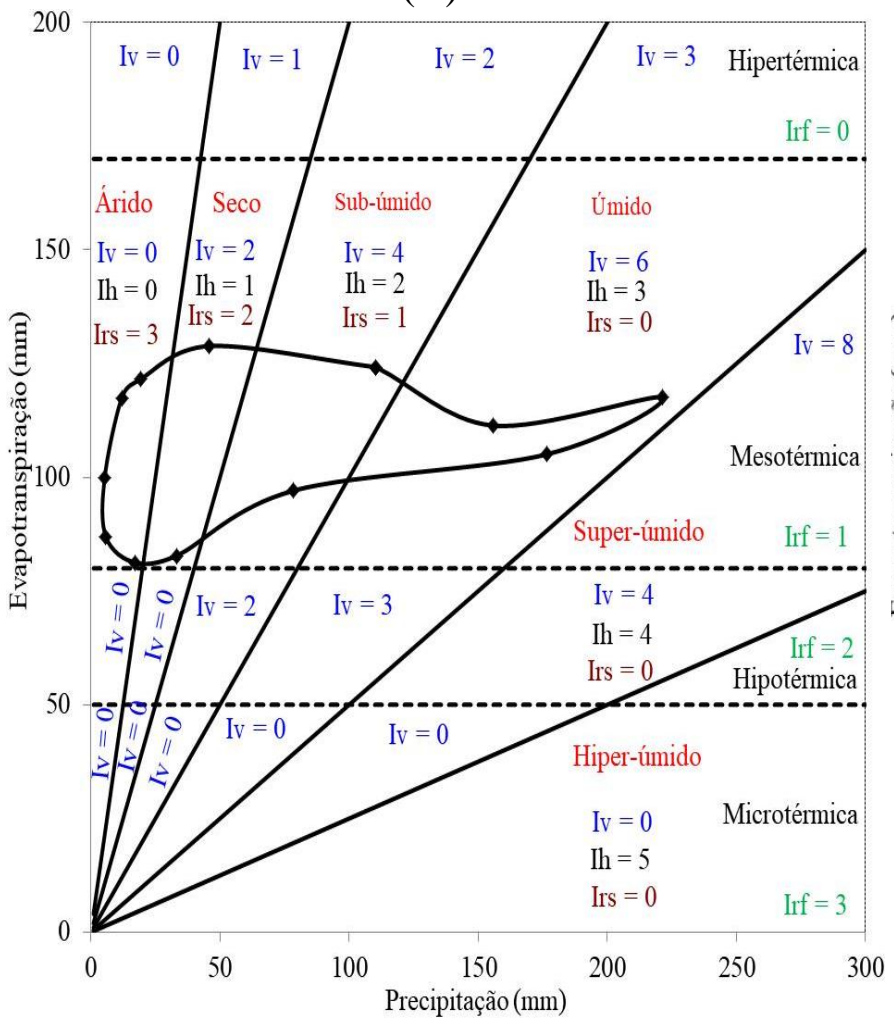

(B)

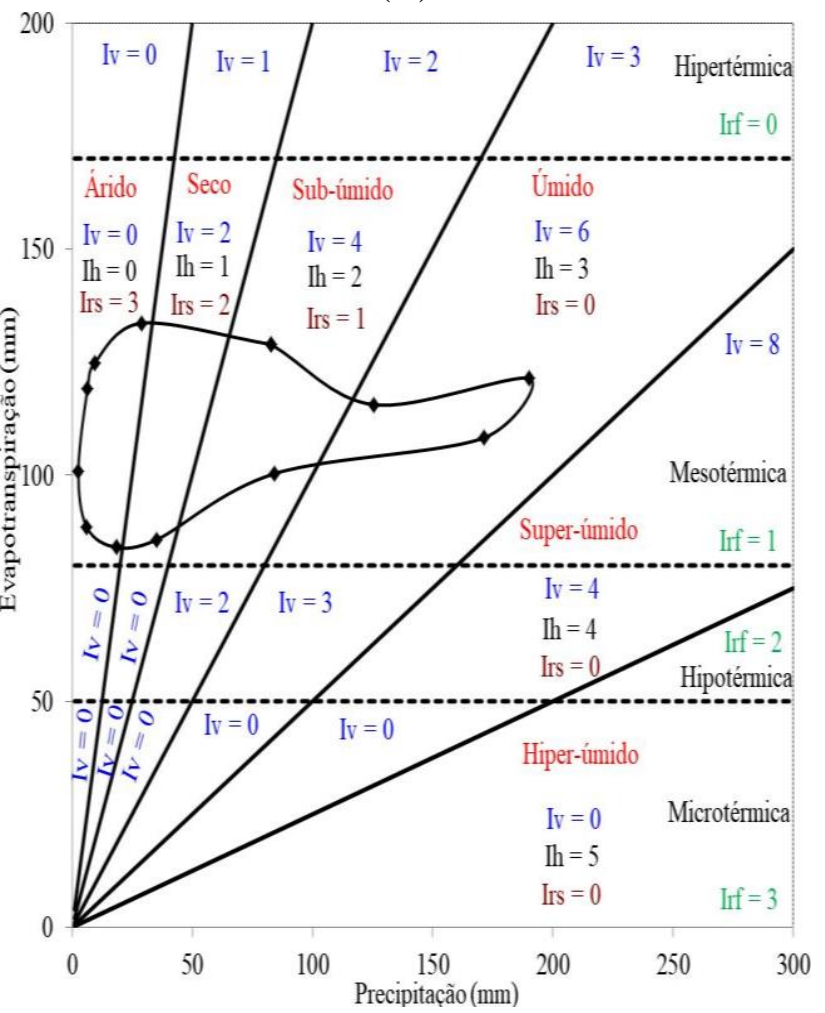

(D)

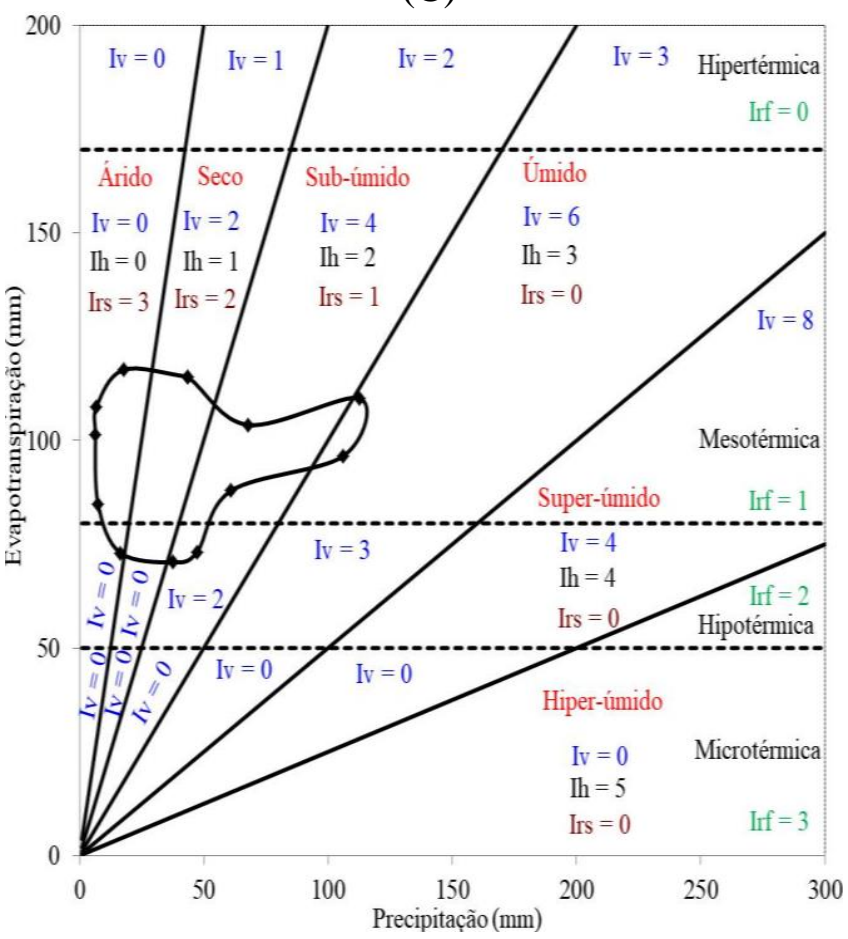

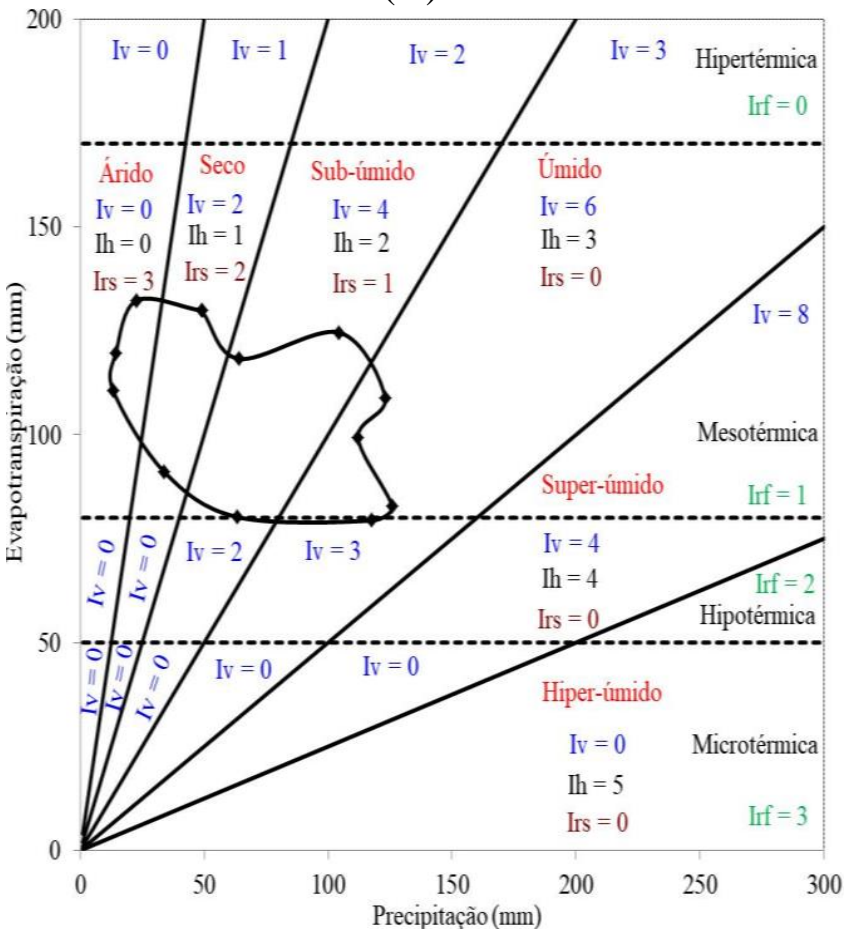


(E)

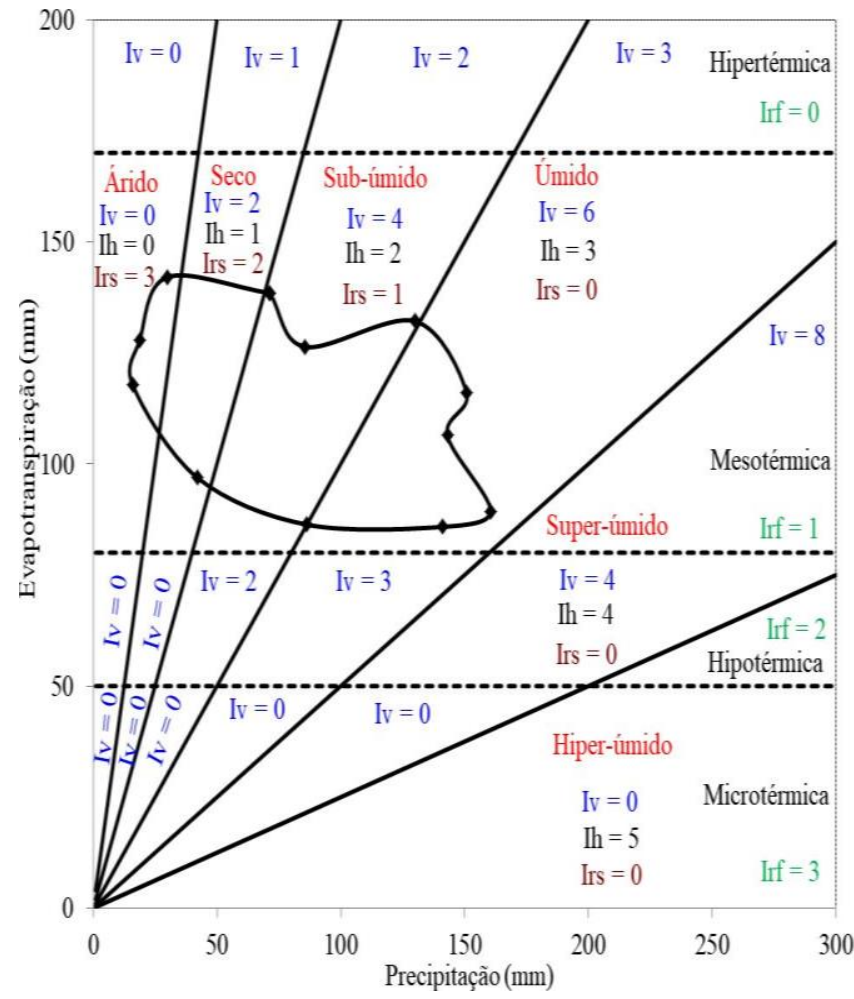

$(\mathrm{F})$

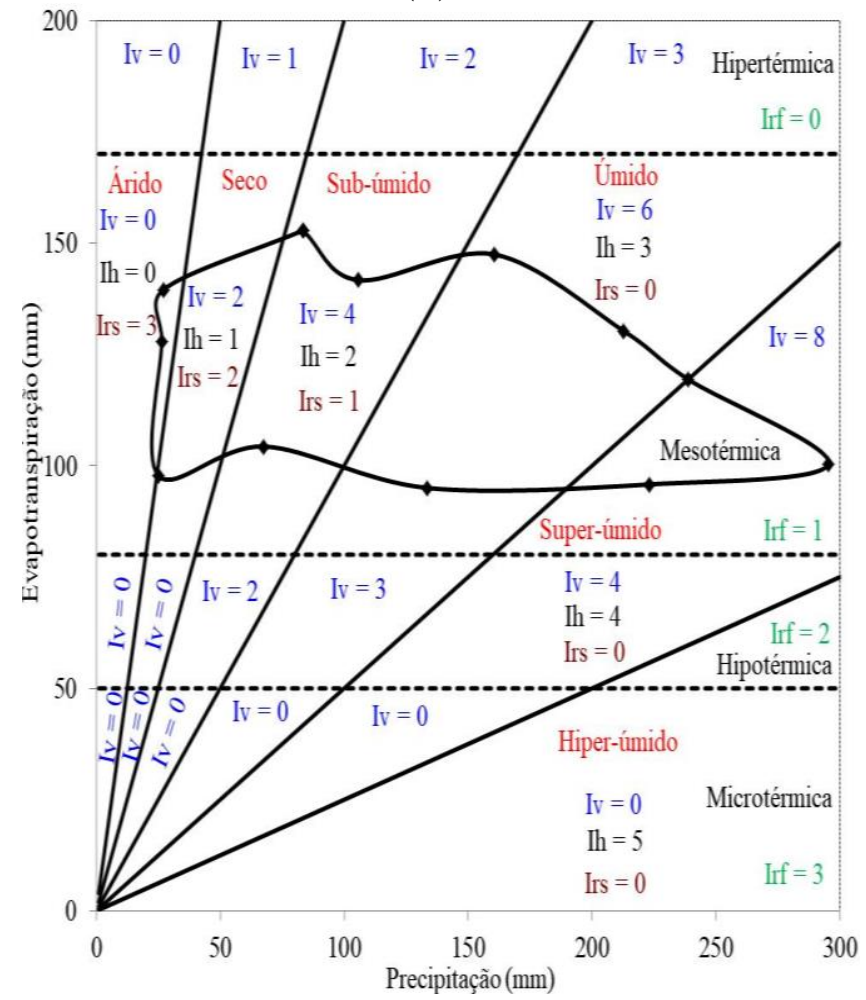

Figura 2. Evapopluviogramas com os setores hídricos e faixas térmicas para o Alto Sertão (A), Sertão (B), Cariri-Curimataú (C), Agreste (D), Brejo (E) e Litoral (F).

Os setores hídricos árido, seco, subsumido, úmido, superúmido e hiperúmido, com vértices comuns no ponto de origem das figuras, correspondem ao gradiente de umidade e são representados através de coeficientes ou índices hídricos (Ih) e por coeficientes ou índices de repouso por seca (Irs).

Observa-se no Alto Sertão que o evapopluviograma possui uma organização anual dos meses em valores médios da interação precipitação versus evapotranspiração, estando em sua maioria, inseridos no setor árido de julho a novembro, porém de fevereiro a abril, enquadram-se no setor úmido. O Sertão possui também maioria inserida no setor hídrico árido (junho a dezembro) e fevereiro a abril no setor úmido, quando observados os índices hídricos e índice de repouso por seca.

No Cariri-Curimataú os meses de agosto a dezembro estão concentrados no setor árido, e sub-úmido de fevereiro a julho. O setor hídrico que as mesorregiões do Agreste e Brejo se enquadram em sua maioria é o úmido (abril a julho), sendo que os meses de outubro a dezembro no setor árido. No Litoral o setor predominante é o úmido, seguido de subúmido, quando observados os índices hídricos e de repouso por seca.

Analisando o evapopluviograma observam-se quatro faixas térmicas que levam em consideração o índice de repouso por frio (Irf), sendo elas Microtérmica, Hipotérmica, Mesotérmica e Hipertérmica (Figura 2). As mesorregiões do Alto Sertão, Sertão, Agreste, Brejo e Litoral enquadram-se na faixa Mesotérmica, já o Cariri-Curimataú em sua maioria se encontram na faixa Mesotérmica, porém com três meses na faixa Hipotérmica. Estes resultados estão de acordo com vários estudos realizados para o semiárido brasileiro (MATOS et al., 2014; MEDEIROS et al., 2015b).

\section{Índices}

Após passarem por fases de cálculos, evapopluviograma e aplicação em tabelas, os resultados dos índices de vegetação (Iv), hídrico (Ih), repouso por seca (Irs) e repouso 
por frio (Irf), encontram-se na Tabela 6. Estes índices estão de acordo com vários estudos realizados para o semiárido (MEDEIROS et al., 2013; RICCE et al., 2014).

Tabela 6. Resumo dos índices de vegetação (Iv), hídrico (Ih), repouso por seca (Irs) e repouso por frio (Irf) para as seis mesorregiões do estado da Paraíba.

\begin{tabular}{cllll}
\hline Mesorregiões & Ih & Iv & Irs & Irf \\
\hline Alto Sertão & 15 & 30 & 21 & 12 \\
Sertão & 14 & 28 & 22 & 12 \\
Cariri-Curimataú & 15 & 26 & 21 & 15 \\
Agreste & 20 & 40 & 16 & 12 \\
Brejo & 21 & 42 & 15 & 12 \\
Litoral & 19 & 54 & 11 & 12 \\
\hline
\end{tabular}

Conforme Thorthwaite (1948), a relação entre o excesso de água do solo e a evapotranspiração potencial ou índice hídrico (Ih), reflete as condições prevalecentes ao longo do ano, abrangendo períodos secos e chuvosos. As mesorregiões do Alto Sertão, Sertão e Cariri-Curimataú apresentam a menor relação precipitação/evapotranspiração.

$O$ índice de vegetação (Iv) indica a capacidade vegetativa da região como uma função das disponibilidades térmicas e hídricas, e representa um índice anual de vegetação de cada localidade. Nota-se que a região do Sertão e Cariri-Curimataú possuem os menores índices de vegetação, fato que se justifica em decorrência dos índices hídricos serem um dos menores observados para as seis mesorregiões estudadas.

O índice de repouso por seca (Irs) evidencia a presença e a intensidade da seca fora do período vegetativo e é obtido considerando-se apenas os pontos (meses) que caem nos setores sub-úmido, seco ou árido, exceto os já incluídos no cômputo do Irs. É possível observar que, dentre as seis mesorregiões analisadas para o estado da Paraíba a mesorregião do Litoral possui o menor (Irs), fato que pode ser explicado por possuir o maior período vegetativo, ou seja, índice de vegetação (Iv).

Quanto ao índice de repouso por frio (Irf) que corresponde às condições térmicas insuficientes para a vegetação normal da cultura. Observa-se que a maioria dos meses possui (Irf) igual a 12 em função do número de meses do ano.

Estes índices indicam as condições para o cultivo de forma sustentável, visando o planejamento para que se obtenha retorno econômico, com base no clima e solo da região, para ser possível a obtenção de maior rentabilidade nos cultivos agrícolas (FRANCISCO et al., 2011).

\section{Aptidão climática}

Os resultados dos índices foram aplicados em relação à Tabela 2 para a determinação da aptidão agroclimática das culturas, conforme apresenta a Tabela 7. 
Tabela 7. Aptidão agroclimática de culturas para as mesorregiões do estado da Paraíba.

\begin{tabular}{|c|c|c|c|c|c|c|}
\hline Mesorregiões & Alto sertão & Sertão & $\begin{array}{c}\text { Cariri- } \\
\text { Curimataú }\end{array}$ & Agreste & Brejo & Litoral \\
\hline Culturas & \multicolumn{6}{|c|}{----------------------------------- Aptidão climática ---------------------------------- } \\
\hline Abacaxi & Plena & Plena & Plena & Plena & Plena & Moderada \\
\hline Algodão herbáceo & Plena & Plena & Plena & Plena & Plena & Plena \\
\hline Banana & Restrita & Restrita & Restrita & Restrita & Restrita & Moderada \\
\hline Caju & Plena & Plena & Plena & Plena & Plena & Plena \\
\hline Cana-de-açúcar & Moderada & Moderada & Restrita & Moderada & Moderada & Moderada \\
\hline Feijão & Plena & Moderada & Moderada & Moderada & Plena & Plena \\
\hline Milho & Plena & Plena & Plena & Plena & Plena & Plena \\
\hline Mamona & Plena & Plena & Plena & Plena & Plena & Plena \\
\hline Sisal & Plena & Plena & Plena & Plena & Plena & Plena \\
\hline Sorgo & Plena & Plena & Plena & Moderada & Restrita & Restrita \\
\hline
\end{tabular}

A partir da determinação da aptidão agroclimática, foi possível observar que algumas culturas são moderadas ou restritas para o cultivo em uma determinada mesorregião em função da elevada deficiência hídrica ocorrida ao longo do ano.

Outros fatores que influenciaram na aptidão, foram os índices hídricos e de vegetação, mais sendo o déficit hídrico o principal fator determinante das condições para a exploração de uma dada cultura em uma determinada região.

Embora a região estudada esteja dentro de uma faixa de temperatura do ar adequada ao desenvolvimento e formação das estruturas reprodutivas das culturas, a deficiência hídrica acentuada limita a exploração das culturas exigentes em grande volume de água (MEDEIROS et al., 2015b).

Matos et al. (2015) afirmam que o uso de sistemas de irrigação é de suma importância, principalmente nos meses que apresentam maior déficit de água no solo, podendo adotar o manejo da irrigação com base nos dados de evapotranspiração e desta forma garantir o desenvolvimento e produtividade máxima das culturas.

Observa-se que as variáveis climáticas como precipitação, temperatura do ar e evapotranspiração são determinantes sobre as condições hídricas e de vegetação de uma determinada região.

\section{CONCLUSÕES}

O deficit de água no solo é o principal fator determinante das condições para a exploração de uma determinada cultura no estado da Paraíba.

As condições agroclimáticas do estado da Paraíba permitiram classificar $80 \%$ das espécies estudadas neste trabalho como aptidão plena, $50 \%$ aptidão moderada e $20 \%$ aptidão restrita.

Para garantir a produtividade das culturas, faz-se necessário planejamento agrícola em $100 \%$ das mesorregiões visando à implantação de sistemas de irrigação com uso racional da água em especial nos períodos de estiagem. 


\section{REFERÊNCIAS BIBLIOGRÁFICAS}

BECKER, C. T.; MEDEIROS, R. M.; FRANCISCO, P. R. M.; GOMES FILHO, M. F. Climatologia da precipitação de Cabaceiras - PB no período entre 1926-2011. Revista Educação Agrícola Superior, v. 28, n. 2, 132-135, 2013. http://dx.doi.org/10.12722/0101-

756X.v28n02a09.

BRITO, J. L. B.; BRAGA, C. C. Chuvas na Paraíba em 2004. Boletim da Sociedade Brasileira de Meteorologia, v. 28, n.1, p. 2732, 2005.

CAVAlCANTI, A. K. G.; LEITE, E. P. F.; D’ANDREA, A. F. Elaboração de mapas de temperatura do ar para o estado da Paraíba utilizando técnicas de interpolação espacial. In: XV Simpósio Brasileiro de Sensoriamento Remoto - SBSR, 15, Curitiba. Anais. Curitiba: 2011. p. 00-48.

CAVALCANTI, E. P.; SILVA, V. P. R.; SOUSA, F. A. S. Programa computacional para a estimativa da temperatura do ar para a região Nordeste do Brasil. Revista Brasileira de Engenharia Agrícola e Ambiental, v. 10, n. $1, \quad$ p. $140-147,2006$. http://dx.doi.org/10.1590/S141543662006000100021 .

FRANCISCO, P. R. M.; MEDEIROS, R. M.; MATOS, R. M.; SANTOS, D.; SABOYA, L. M. F. Evapotranspiração de referência mensal e anual pelo método de Thornthwaite para o estado da Paraíba. Revista Brasileira de Climatologia, v. 20, n. 1, p. 135-147, 2017. http://dx.doi.org/10.5380/abclima.v20i0.41569

FRANCISCO, P. R. M.; MEDEIROS, R. M.; SANTOS, D. Oscilações pluviométricas e temperatura média do ar em seis regiões homogêneas do estado da Paraíba. In: IV Workshop Internacional sobre Mudanças Climáticas e Biodiversidade, Recife, Anais... Recife: 2015b.
FRANCISCO, P. R. M.; PEREIRA, F. C.; MEDEIROS, R. M.; SÁ, T. F. F. Zoneamento de risco climático e aptidão de cultivo para o município de Picui - PB. Revista Brasileira de Geografia Física, v. 4, n. 5, p. 1043-1055, 2011.

FRANCISCO, P. R. M.; MEDEIROS, R. M.; MATOS, R. M.; BANDEIRA, M. M.; SANTOS, D. Análise e Mapeamento dos Índices de Umidade, Hídrico e Aridez através do BHC para o Estado da Paraíba. Revista Brasileira de Geografia Física, v. 8, n. 4, 1093-1108, $2015 \mathrm{a}$. http://dx.doi.org/10.5935/19842295.20150056 .

MATOS, R. M.; MEDEIROS, R. M.; FRANCISCO, P. R. M.; SILVA, P. F.; SANTOS, D. Caracterização e aptidão climática de culturas para o município de Alhandra - PB, Brasil. Revista Brasileira de Agricultura Irrigada, v. 9, n. 3, p. 183-192, 2015. 10.7127/rbai.v9n300288.

MATOS, R. M.; SILVA, J. A. S.; MEDEIROS, R. M. Aptidão climática para a cultura do feijão caupi do município de Barbalha - CE. Revista Brasileira de Agricultura Irrigada, v. 8, n. 6, p. 422-431, 2014. 10.7127/rbai.v8n600240.

MEDEIROS, R. M.; AZEVEDO, P. V.; SABOYA, L. M. F.; FRANCISCO, P. R. M. Classificação climática e zoneamento agroclimático para o município de Amarante PI. Revista Brasileira de Agricultura Irrigada, v. 7, n. 2, p. 170-180, 2013. 10.7127/rbai.v7n200011.

MEDEIROS, R. M.; MATOS, R. M.; SABOYA, L. M. F.; SILVA, P. F. Aptidão agroclimática para o cultivo da videira (Vitis Vinifera L.) no estado da Paraíba. Revista Brasileira de Agricultura Irrigada, v. 11, n. 3, p. 1492-1499, 2017. 10.7127/rbai.v11n300511.

MEDEIROS, R. M.; MATOS, R. M.; SILVA, P. F.; SILVA, J. A. S.; FRANCISCO, P. R. M. 
Caracterização climática e diagnóstico da aptidão agroclimática de culturas para Barbalha - CE. Enciclopédia Biosfera, v. 11, n. 21, p. 461-476, 2015b.

MEDEIROS, R. M.; FRANCISCO, P. R. M.; MATOS, R. M.; SANTOS, D.; SOUSA, T. P. Caracterização agroclimática e aptidão de culturas para diferentes municípios e regiões da Paraíba. Revista Agropecuária Científica no Semi-Árido, v. 11, n. 2, p. 99-110, 2015a. http://dx.doi.org/10.30969/acsa.v11i2.614.

MORAIS NETO, J.; BARBOSA, M. P.; ARAÚJO, A. E. Efeito dos eventos ENOS e das TSM na variação pluviométrica do semiárido paraibano. Revista Brasileira de Engenharia Agrícola Ambiental, v. 11, n. 1, p. 61-66, 2007.

NEVES, S. M. A. S.; NUNES, M. C. M.; NEVES, R. J. Caracterização das condições climáticas de Cáceres/MT - Brasil, no período de 1971 a 2009: subsídio às atividades agropecuárias e turísticas municipais. Boletim Goiano de Geografia, v. 31, n. 2, p. 55-68, 2011. 10.5216/bgg.V31i2.16845.

OMETTO, J. C. Bioclimatologia vegetal. São Paulo: Ed. Agronômica Ceres Ltda., 413p. 1981.

PASSOS, M. L.V.; ZAMBRZYCKI, G. C.; PEREIRA, R. S. Balanço hídrico climatológico e classificação climática para o município de Balsas-MA. Revista Scientia Agraria, v. 18, n. 1, p. 83-89, 2017. http://dx.doi.org/10.5380/rsa.v18i1.48584.

RICCE, W. S.; CARVALHO, S. L. C.; CARAMORI, P. H.; AULER, P. A. M.; ROBERTO, S. R. Zoneamento agroclimático da cultura do abacaxizeiro no Estado do Paraná. Revista Semina, v. 35, n. 4, p. 2337$2346.2014 .210 .5433 / 1679$ 0359.2014v35n4Suplp2337.
SANTOS, G. O.; HERNANDEZ, F. B. T.; ROSSETTI, J. C. Balanço hídrico como ferramenta ao planejamento agropecuário para a região de Marinópolis, noroeste do estado de São Paulo. Revista Brasileira de Agricultura Irrigada, v. 4, n. 3, p. 142-149, 2010.

SILVA, V. C.; LUCENA, D. B. Variabilidade interanual e espacial da precipitação com dados do CPC para o alto sertão paraibano. In: II Workshop Internacional sobre Água no Semiárido Brasileiro, Anais. Campina Grande: 2015.

SILVA, V. M. A.; MEDEIROS R. M; ARAUJO, S. M. S. Desertificação e variabilidade pluviométrica em São João do Cariri - PB no período de 1911-2010 In: I Workshop Internacional sobre Água no Semiárido Brasileiro, Campina Grande, Anais... Campina Grande: 2013.

THORNTHWAITE, C. W. An approach towards a rational classification of climate. Geographical Review, v. 38, n. 1, p. 55-94, 1948. 10.2307/210739.

THORNTHWAITE, $\quad$ C. W.; MATHER, J. R. The water balance. Publication in Climatology, n. 8. Laboratory of Climatology. Centerton, N. J., 1955.

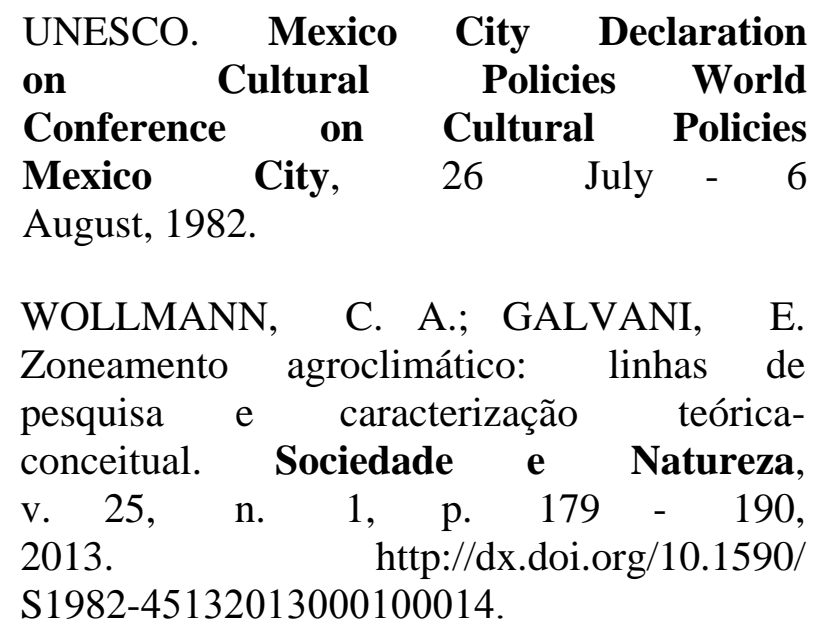

